\title{
The Mediterranean diet, an environmentally friendly option: evidence from the Seguimiento Universidad de Navarra (SUN) cohort
}

\author{
Ujué Fresán $1, *$, Miguel-Angel Martínez-Gonzalez ${ }^{1,2,3}$, Joan Sabaté ${ }^{4}$ and \\ Maira Bes-Rastrollo 1,2,3 \\ 'Department of Preventive Medicine and Public Health, University of Navarra, Medical School, Irunlarrea 1, 31008 \\ Pamplona, Spain: ${ }^{2}$ Navarra Institute for Health Research (IdisNa), Pamplona, Spain: ${ }^{3} \mathrm{ClBER}$ Physiopathology of \\ Obesity and Nutrition (CIBERobn), Carlos III Institute of Health, Madrid, Spain: ${ }^{4}$ Center for Nutrition, Healthy \\ Lifestyles, and Disease Prevention, Loma Linda University, Loma Linda, CA, USA
}

Submitted 20 September 2017: Final revision received 27 November 2017: Accepted 30 November 2017: First published online 30 January 2018

\begin{abstract}
Objective: How food is produced and consumed has consequences for ecosystems, such as resource use and greenhouse gas (GHG) emission among others. The Mediterranean diet (MedDiet) was proposed as a sustainable dietary model, due to its nutritional, environmental, economic and sociocultural dimensions. However, further evidence is needed. Thus, our objective was to evaluate the impact on resource (land, water and energy) use and GHG emission of better adherence to the MedDiet in a Mediterranean Spanish cohort.

Design: We analysed the dietary pattern of participants through a validated FFQ. The outcomes were land use, water and energy consumption and GHG emission according to MedDiet adherence. The specific environmental footprints of food item production and processing were obtained from different available life-cycle assessments.

Setting: Spanish university graduates.

Subjects: Participants ( $n 20$ 363) in the Seguimiento Universidad de Navarra (SUN) cohort.

Results: Better adherence to the MedDiet was associated with lower land use $\left(-0.71(95 \% \mathrm{CI}-0.76,-0.66) \mathrm{m}^{2} / \mathrm{d}\right)$, water consumption $(-58.88(95 \% \mathrm{CI}-90 \cdot 12$, $-27.64)$ litres/d), energy consumption $(-0.86$ (95\% CI $-1.01,-0.70) \mathrm{MJ} / \mathrm{d})$ and GHG emission ( $\left.-0.73(95 \% \mathrm{CI}-0.78,-0.69) \mathrm{kg} \mathrm{CO}_{2} \mathrm{e} / \mathrm{d}\right)$. A statistically significant linear trend $(P<0.05)$ was observed in all these analyses.

Conclusions: In this Mediterranean cohort, better adherence to the MedDiet was an eco-friendly option according to resource consumption and GHG emission.
\end{abstract}

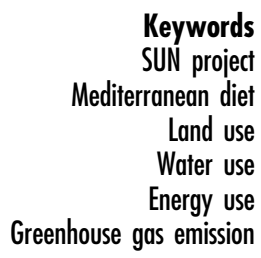

Keywords anean diet

Energy use

Greenhouse gas emission
The Mediterranean diet (MedDiet) is characterized by the consumption of high amounts of vegetables, cereals (mostly unrefined), legumes, nuts and olive oil as the main source of fats, moderate intakes of fish and dairy products, low quantities of meat and meat products, and an optional moderate wine consumption ${ }^{(1-3)}$. Epidemiological studies have associated the MedDiet with a higher nutrient adequacy $^{(4,5)}$ and several investigations confirm its role in prevention of chronic diseases ${ }^{(6-13)}$. Moreover, this pattern should not be considered like a set of foods only, but also as a cultural model. The United Nations Educational, Scientific and Cultural Organization acknowledged it as an Intangible Cultural Heritage of Humanity, stating that: 'The Mediterranean diet involves a set of skills, knowledge, rituals, symbols and traditions concerning crops, harvesting, fishing, animal husbandry, conservation, processing, cooking, and particularly the sharing and consumption of food ${ }^{,(14)}$

Beyond the prevention of chronic diseases in the present generation, there are further potential future advantages for next generations by increasing population adherence to a healthy dietary model. The way food is produced, processed, distributed and consumed has consequences not only for human health but also for ecosystems ${ }^{(15,16)}$. Environmental footprints are caused by resource consumption (such as land, water and energy) and greenhouse gas (GHG) emission, among others. The impact on the environment differs among food items ${ }^{(17)}$; for example, vegetable-based foods have lower environmental impact compared with foods coming from 
animals $^{(18-20)}$. Sustainable diets have been defined as 'those diets with low environmental impacts which contribute to food and nutrition security and to healthy life for present and future generations. Sustainable diets are protective and respectful of biodiversity and ecosystems, culturally acceptable, accessible, economically fair and affordable; nutritionally adequate, safe and healthy; while optimizing natural and human resources, ${ }^{,(21)}$.

In the 1990s, Gussow started studying the MedDiet according to its impact on the environment ${ }^{(22)}$, and in 2009, the MedDiet was declared a sustainable dietary model due to its nutritional, environmental, economic and sociocultural dimensions ${ }^{(23-25)}$. From then on, the new version of the Mediterranean diet pyramid, for the first time, included not only the main characteristic foods but also biodiversity and eco-friendly products ${ }^{(1)}$. Some economic and sociocultural factors, like lifestyle changes and food globalization, are responsible for the current decreasing adherence to the MedDiet, as is happening in the Spanish population ${ }^{(26-28)}$.

Thus, our objective was to evaluate the impact on resource (land, water and energy) use and GHG emission of a Mediterranean Spanish cohort according to adherence to the Mediterranean diet ${ }^{(29)}$.

\section{Methods}

\section{Study population}

The Spanish project Seguimiento Universidad de Navarra (University of Navarra Follow-up; SUN) is an ongoing, multipurpose, dynamic cohort of university graduates conducted in Spain. It started in December 1999, and the recruitment of participants is permanently open. When participants are invited to enter the study, they receive the baseline questionnaire and a letter which explains all information about the SUN cohort, including how to withdraw from the study. Voluntary completion of the baseline questionnaire implies the informed consent. Every two years, information from participants is collected by mailed or emailed questionnaires. Further details of the study design and methods have been published elsewhere ${ }^{(30-32)}$.

Up to December 2015, 22476 participants were recruited. Among them, we excluded 2113 with total energy intake outside predefined limits $(<3347$ and $2092 \mathrm{~kJ} / \mathrm{d}$ $(<800$ and $<500 \mathrm{kcal} / \mathrm{d})$ or $>16736$ and $>14644 \mathrm{~kJ} / \mathrm{d}$ ( $>4000$ and $>3500 \mathrm{kcal} / \mathrm{d}$ ) for men and women, respectively) ${ }^{(33)}$. Therefore, the final number of participants for the current analysis was 20363.

\section{Exposure assessment}

Dietary intake was recorded using a semi-quantitative FFQ (136 food items) completed at baseline. On it, food items were classified into the following groups: dairy products; eggs and meat; fish and seafood; vegetables; fruits; legumes; cereals; fats and oils; pastries; drinks; and others.
The validity and reproducibility of this questionnaire were previously reported $^{(34)}$ and recently re-evaluated ${ }^{(35,36)}$. For example, it showed reasonably good validity for assessing the different food groups (intraclass correlation coefficients $v$. four $3 \mathrm{~d}$ food records ranged from 0.40 to $0 \cdot 84$ ). Of all food items, we did not assess honey or honeyderived products such as nougat, due to the difficulties of getting objectively quantified values. Processed products were assessed according to their ingredients; most of the recipes for bakery and other products came from a Spanish recipe book ${ }^{(37)}$.

To measure the adherence of each participant to the Mediterranean pattern, we used the nine-item MedDiet index (vegetables, legumes, fruits and nuts, cereals, fish, meat and meat products, whole-fat dairy products, alcohol and fat (as the ratio of monounsaturated to saturated fat intakes)) proposed by Trichopoulou et al. ${ }^{(29)}$. A score of 0 or 1 point was given to each of these nine components, with the use of the sex-specific medians as the cut-offs. For the presumed beneficial components (vegetables, legumes, fruits and nuts, cereals, fish and fat ratio), those participants who consumed that food group below their sex-specific median were assigned a value of 0 , and participants whose consumption was at or above the median were assigned 1 point. On the contrary, for detrimental items such as meat and meat products and whole-fat dairy products, consumption below the median was assigned 1 point, and at or above the median was scored as 0. For ethanol, a value of 1 was assigned if the intake was between 10 and $50 \mathrm{~g} / \mathrm{d}$ or 5 and $25 \mathrm{~g} / \mathrm{d}$ for men or women, respectively. The total score ranged from 0 to 9 points (minimal to maximal adherence to MedDiet). We established four major categories of MedDiet score: $\leq 2$ points (low adherence; reference), 3-4 points, 5-6 points and $\geq 7$ points (high adherence).

\section{Outcome assessment}

We estimated the impact of each food item on land, water and energy use and GHG emission. We assessed the impact of food item production and processing only (except for land use, which included crops and livestock production, but not land related to food processing) and just conventional agriculture processes. For that purpose, we used several information sources of secondary data (see the online supplementary material for the main ones).

The specific value that a serving of each item had in relation to resource use or GHG emission was multiplied by the number of servings of that item consumed per day by each participant, obtaining the daily impact of each food item on the four outcomes. We summed the values of all food items, obtaining the impact on the water, land and energy use and GHG emission of the daily diet of each participant. Apart from assessing these four outcomes on their own, we also proposed a sustainability score based on the total environmental footprint. As in Trichopoulou et al.'s score, 0 or 1 point was given to each of these four 
components, using the sex-specific medians as the cutoffs. This time, a use/emission below or at the median was assigned 1 point, and otherwise it was scored as 0 . The total score ranged from 0 to 4 points; the higher the score, the eco-friendlier the dietary pattern.

Some general considerations should be borne in mind: liver was considered derived from pork and beef, $50 \%$ each of them; entrails from pork, beef and lamb, 33\% of each one; sausages, foie gras, meatballs and other meat products from pork; hamburgers from beef; fish was considered from aquaculture and fresh; 'white fish' included hake, seabream and sole; 'blue fish' included sardines, tuna and salmon; vegetables, fruits and legumes were assessed as not having processing (with the exception of fruit in syrup or in their own juice, dry fruits and French fries); if an item gathered two or more food products (e.g. apple and pear appeared as only one item), we considered the outcome value of that item as the mean value of all the foods that it contained. Although we obtained information for the majority of food items, for a few of them we did not have available data on their environmental sustainability characteristics. In those cases, we assigned to that item the value of the most similar one (as is the case for energy data of some vegetables).

The data sets generated and/or analysed during the current study are available from the corresponding author upon request.

\section{Statistical analyses}

Linear regression models were used to assess the relationship between the four categories of adherence to the MedDiet ( $\leq 2 ; 3-4 ; 5-6 ; \geq 7$ points) and land use, water and energy consumption and GHG emission, separately. The first category ( $\leq 2$ points) was used as the reference category and three dummy variables were included for the three upper categories of adherence to the MedDiet. Moreover, we performed the same analyses for the total sustainability score. We estimated means and their 95\% CI for each of the categories of the MedDiet, adjusting for energy as a potential confounder. Linear trends were analysed by introducing the Mediterranean score as a continuous variable in the models.

To calculate the contribution of each item to the betweenperson variability in outcomes, we conducted nested regression analyses after a stepwise selection algorithm. The contribution of each item is shown in the cumulative $R^{2}$ change. Furthermore, we estimated the contribution of each item in relation to environmental footprints, dividing its value by total use/emission of the measured outcome (\%), for land use, water consumption, energy consumption and GHG emission, separately. We repeated the percentage contribution analysis gathering the items into food groups based on those presented in the baseline FFQ.

All $P$ values presented are two-tailed; $P<0.05$ was considered statistically significant. Analyses were performed using the statistical software package STATA/SE version 12.1.

\section{Results}

Our analysis included a total of 20363 participants (8098 men and 12265 women). The principal baseline characteristics of participants across categories of MedDiet adherence are presented in Table 1. Participants with better adherence to the MedDiet compared with those in the poorest adherence category were more likely to have higher total energy intake. On average, they consumed more non-fat/low-fat dairy products, but less total and whole-fat dairy. They consumed more fish and seafood, vegetables, fruits, legumes, cereals and beverages (especially water, red wine and other alcoholic beverage, but less sugar-sweetened sodas). The consumption of pastries, eggs and meat (any kind) was lower in the categories of higher adherence to the MedDiet. According to nutrient intakes, participants with better MedDiet adherence consumed fewer fats, especially SFA, although a higher quantity of olive oil. Their intakes of carbohydrates, dietary fibre and alcohol were higher. They were more prone to be older, married, former smokers and attained a higher level of university education.

Analysing land use, higher adherence to the MedDiet was associated with lower land use with multivariableadjusted differences of $-0.13(95 \% \mathrm{CI}-0 \cdot 17,-0 \cdot 09) \mathrm{m}^{2} / \mathrm{d}$, $-0.39(95 \% \mathrm{CI}-0.44,-0.35) \mathrm{m}^{2} / \mathrm{d}$ and $-0.71(95 \% \mathrm{CI}$ $-0.76,-0.66) \mathrm{m}^{2} / \mathrm{d}$ for MedDiet adherence of 3-4, 5-6 and $\geq 7$ points, respectively, compared with the reference category of lowest adherence $(\leq 2$ points; $P$ for trend $<0 \cdot 001$; Fig. 1(a)).

An inverse association between water use and adherence to the MedDiet was also observed when comparing the highest category ( $\geq 7$ points) $v . \leq 2$ points $(-58.88$ (95\% CI $-90 \cdot 12,-27 \cdot 64)$ litres/d). There was a statistically significant linear trend for all the categories ( $P$ for trend $=0.009$ ), although the second category (3-4 points) showed higher water use than the reference category $(+23.79$ (95\% CI +0.07, +47.51) litres/d), while the third category showed no relationship $(+21.44$ (95\% CI -2.69 , $+45 \cdot 47)$ litres/d) with respect to the lowest adherence ( $\leq 2$ points) category (Fig. 1(b)).

Energy use decreased as MedDiet adherence increased: $-0 \cdot 14(95 \% \mathrm{CI}-0 \cdot 26,-0 \cdot 02) \mathrm{MJ} / \mathrm{d},-0.46$ (95\% CI -0.58 , $-0.34) \mathrm{MJ} / \mathrm{d}$ and $-0.86(95 \% \mathrm{CI}-1 \cdot 01,-0 \cdot 70) \mathrm{MJ} / \mathrm{d}$ for $3-4$, $5-6$ and $\geq 7$ points of adherence to the MedDiet, respectively, compared with the reference ( $\leq 2$ points; $P$ for trend <0.001; Fig. 1(c)).

The same impact was observed for GHG emission. Less GHG were emitted as the adherence to the MedDiet increased $(-0 \cdot 17(95 \% \mathrm{CI}-0 \cdot 20,-0 \cdot 14) \mathrm{kg} \mathrm{CO} 2 \mathrm{e} / \mathrm{d},-0 \cdot 40$ (95\% CI $-0.43,-0.37) \mathrm{kg} \mathrm{CO}_{2} \mathrm{e} / \mathrm{d}$ and -0.73 (95\% CI $-0 \cdot 78,-0.69) \mathrm{kg} \mathrm{CO}_{2} \mathrm{e} / \mathrm{d}$, for MedDiet adherence of 3-4, 5-6 and $\geq 7$ points compared with the reference $(\leq 2$ points), respectively; $P$ for trend $<0 \cdot 001$; Fig. 1(d)).

Finally, when we analysed all environmental aspects together in a combined sustainability score (Fig. 1(e)), we 
Table 1 Distribution of baseline characteristics according to adherence to the Mediterranean diet (MedDiet) among 20363 participants in the Seguimiento Universidad de Navarra (SUN) cohort, 1999-2015

\begin{tabular}{|c|c|c|c|c|c|c|c|c|}
\hline & \multicolumn{8}{|c|}{ MedDiet adherence* } \\
\hline & \multicolumn{2}{|c|}{$\begin{array}{c}\leq 2 \text { points } \\
(n 3328)\end{array}$} & \multicolumn{2}{|c|}{$\begin{array}{c}\text { 3-4 points } \\
(n 7571)\end{array}$} & \multicolumn{2}{|c|}{$\begin{array}{c}\text { 5-6 points } \\
(n 7173)\end{array}$} & \multicolumn{2}{|c|}{$\begin{array}{c}\geq 7 \text { points } \\
\text { (n 2291) }\end{array}$} \\
\hline & Mean & SD & Mean & SD & Mean & SD & Mean & SD \\
\hline \multicolumn{9}{|l|}{ Food and nutrition } \\
\hline Total energy intake (kJ/d) & 9184 & 2502 & 9506 & 2636 & 10004 & 2556 & 10569 & 2297 \\
\hline Total energy intake (kcal/d) & 2195 & 598 & 2272 & 630 & 2391 & 611 & 2526 & 549 \\
\hline \multicolumn{9}{|l|}{ Food (servings/d) } \\
\hline Dairy products & 3.21 & 1.68 & 3.07 & 1.78 & 2.85 & 1.66 & 2.75 & 1.61 \\
\hline Non-fat/low-fat dairy products & 0.89 & 1.21 & 1.30 & 1.40 & 1.56 & 1.47 & 1.87 & 1.53 \\
\hline Fatty dairy products & $2 \cdot 32$ & 1.45 & 1.77 & 1.35 & 1.29 & $1 \cdot 10$ & 0.88 & 0.75 \\
\hline Eggs & 0.40 & 0.27 & 0.39 & 0.28 & 0.38 & 0.25 & 0.37 & 0.23 \\
\hline All types of meats & 2.48 & 1.02 & $2 \cdot 30$ & 0.97 & $2 \cdot 14$ & 0.96 & 1.84 & 0.81 \\
\hline Processed meat & $1 \cdot 18$ & 0.79 & 1.06 & 0.68 & 0.97 & 0.66 & 0.80 & 0.54 \\
\hline Red meat & 0.59 & 0.32 & 0.53 & 0.31 & 0.48 & 0.30 & 0.39 & 0.26 \\
\hline White meat & 0.32 & 0.26 & 0.31 & 0.24 & 0.32 & 0.25 & 0.29 & 0.21 \\
\hline Fish and seafood & 0.47 & 0.29 & 0.64 & 0.40 & 0.83 & 0.46 & 0.99 & 0.44 \\
\hline Vegetables & 1.74 & 0.89 & $2 \cdot 36$ & 1.31 & $3 \cdot 12$ & 1.66 & 3.71 & 1.64 \\
\hline Fruits & 1.53 & 1.07 & $2 \cdot 38$ & 1.74 & 3.41 & $2 \cdot 23$ & 4.36 & 2.48 \\
\hline Legumes & 0.28 & 0.25 & 0.36 & 0.31 & 0.42 & 0.31 & 0.48 & 0.30 \\
\hline Cereals & 1.40 & 0.98 & 1.69 & 1.21 & 2.03 & 1.33 & 2.60 & 1.38 \\
\hline Oils and fats & 1.32 & 1.23 & 1.73 & 1.45 & $2 \cdot 13$ & 1.63 & 2.49 & 1.63 \\
\hline Olive oil & 0.86 & 0.90 & 1.33 & 1.26 & 1.75 & 1.43 & $2 \cdot 16$ & 1.46 \\
\hline Pastry products & $1 \cdot 16$ & 1.02 & 1.04 & 0.92 & 0.94 & 0.87 & 0.80 & 0.77 \\
\hline Beverages & $6 \cdot 33$ & 3.25 & 6.90 & 3.24 & $7 \cdot 29$ & 3.24 & 7.82 & 3.27 \\
\hline Water & 4.08 & $2 \cdot 60$ & 4.36 & 2.62 & 4.62 & 2.63 & 4.89 & $2 \cdot 65$ \\
\hline Red wine & 0.03 & 0.19 & 0.05 & 0.25 & 0.06 & 0.24 & 0.08 & 0.27 \\
\hline Other alcoholic beverages & 0.21 & 0.46 & 0.29 & 0.54 & 0.34 & 0.53 & 0.45 & 0.54 \\
\hline Sugared sodas & 0.29 & 0.54 & 0.22 & 0.42 & 0.17 & 0.33 & 0.12 & 0.30 \\
\hline \multicolumn{9}{|c|}{ Nutrient intake (\% total energy intake/d) } \\
\hline Fat & 40 & 6 & 38 & 6 & 35 & 6 & 33 & 6 \\
\hline SFA & 15 & 3 & 13 & 3 & 11 & 3 & 10 & 2 \\
\hline MUFA & 16 & 3 & 16 & 4 & 16 & 4 & 15 & 4 \\
\hline PUFA & 5 & 2 & 5 & 2 & 5 & 2 & 5 & 2 \\
\hline Carbohydrates & 41 & $\overline{7}$ & 42 & $\overline{7}$ & 45 & 7 & 47 & $\overline{7}$ \\
\hline Protein & 18 & 4 & 18 & 4 & 18 & 3 & 18 & 3 \\
\hline Dietary fibre intake $(\mathrm{g} / \mathrm{d})$ & 18 & 7 & 25 & 10 & 32 & 12 & 40 & 13 \\
\hline Alcohol intake $(\mathrm{g} / \mathrm{d})$ & 3 & 7 & 4 & 8 & 5 & 8 & 7 & 8 \\
\hline \multicolumn{9}{|l|}{ Sociodemographic data } \\
\hline Sex (\% men) & \multicolumn{2}{|c|}{40} & \multicolumn{2}{|c|}{39} & \multicolumn{2}{|c|}{40} & \multicolumn{2}{|c|}{42} \\
\hline Age (years) & $34 \cdot 1$ & 10.5 & 37 & 11.7 & $40 \cdot 1$ & $12 \cdot 7$ & $42 \cdot 6$ & 13.0 \\
\hline Civil status (\%) & & & & & & & & \\
\hline Single & \multicolumn{2}{|c|}{55} & \multicolumn{2}{|c|}{47} & \multicolumn{2}{|c|}{41} & \multicolumn{2}{|c|}{36} \\
\hline Married & \multicolumn{2}{|c|}{41} & \multicolumn{2}{|c|}{49} & & & & \\
\hline Others & & & & & & & & \\
\hline Smoking status (\%) & & & & & & & & \\
\hline Current smoker & & & & & & & & \\
\hline Former smoker & & & & & & & & \\
\hline Educational level (\%) & & & & & & & & \\
\hline Technical/non-graduated & & & & & & & & \\
\hline Graduated & & & & & & & & \\
\hline Master/doctoral & & & & & & & & \\
\hline
\end{tabular}

Values are presented as mean and SD, unless indicated otherwise.

*According to Trichopoulou et al.'s score ${ }^{(29)}$.

observed a statistically significant linear trend across all categories of adherence to the MedDiet $(P$ for trend $<0 \cdot 001)$. This means that the higher the adherence to the MedDiet, the eco-friendlier were the nutritional options. A statistically positive association was reported for the highest ( $\geq 7$ points) and third (5-6 points) category with respect to the lowest one $(0.24$ (95\% CI $0.20,0.29)$ points and 0.12 (95\% CI $0.08,0.15)$ points, respectively), but there was no significant difference between the second category ( $3-4$ points) and the lowest ( $\leq 2$ points) category (0.01 (95\% CI $-0.02,0.04)$ points).

After analysing the main sources of variability in the four studied environmental footprints, we concluded that: beef meat, chocolate cookies, old cheese, regular coffee and French fries were the most representative items influencing our results for the land-use analysis 
(a)

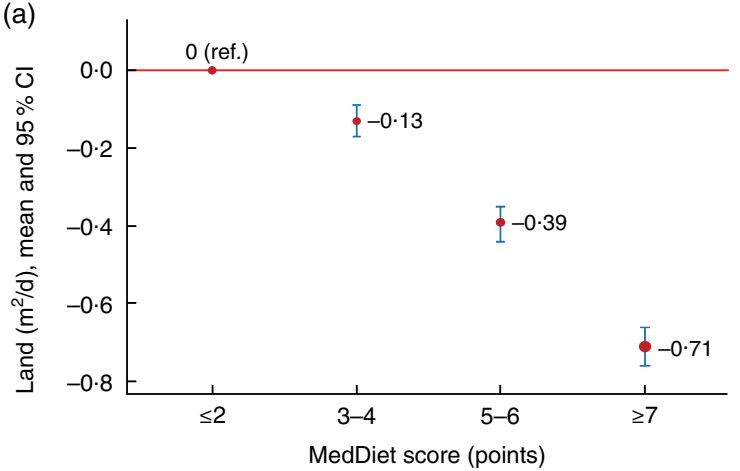

(c)

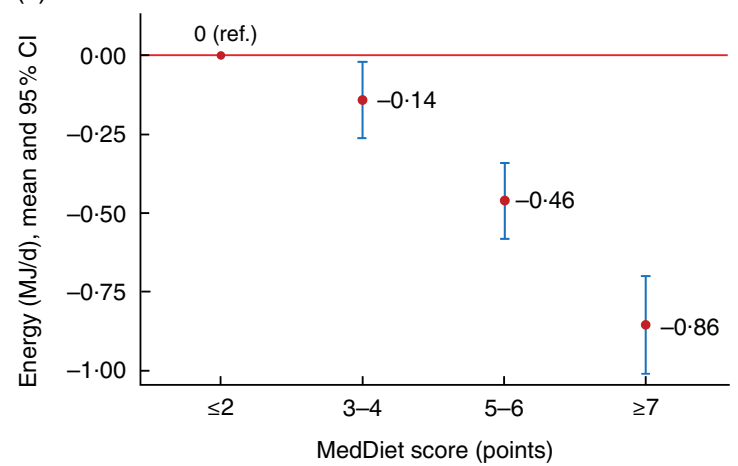

(b)

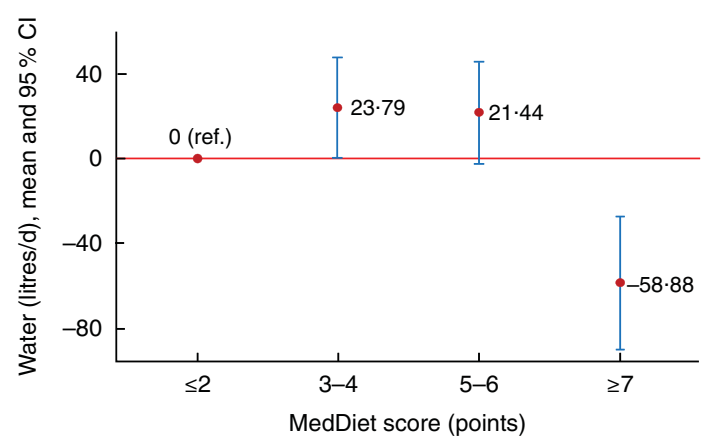

(d)

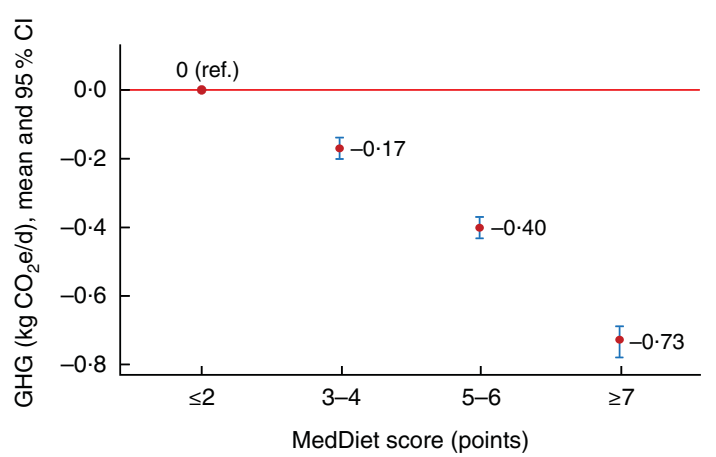

(e)

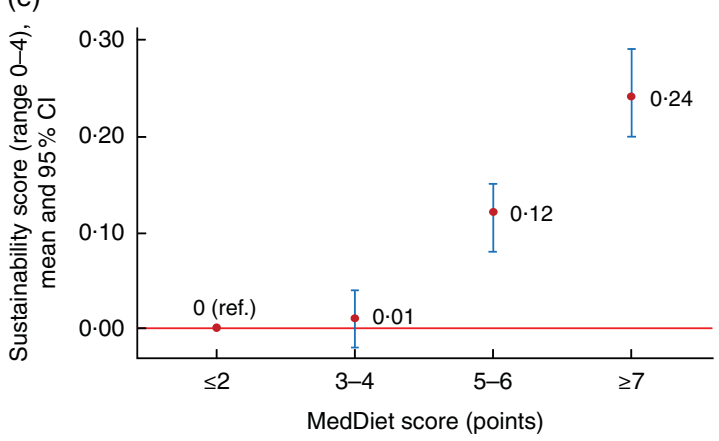

Fig. 1 (colour online) Land use (a), water consumption (b), energy consumption (c), greenhouse gas (GHG) emission (d) and sustainability score (e) according to adherence to the Mediterranean diet (MedDiet) among 20363 participants in the Seguimiento Universidad de Navarra (SUN) cohort, 1999-2015. Red circles represent relative means with respect to the reference (ref.) and vertical bars represent their $95 \% \mathrm{Cl}$. MedDiet adherence calculated according to Trichopoulou et al.'s score ${ }^{(29)}$ and outcomes adjusted for total energy intake. (a) $P$ trend $<0.001$; (b) $P$ trend $=0.009$; (c) $P$ trend $<0.001$; (d) $P$ trend $<0.001$; (e) $P$ trend $<0.001$

(all together: $\left.R^{2}=0 \cdot 47\right)$; beef meat, olive oil, pork meat, cured ham and asparagus, for water consumption (all together: $\left.R^{2}=0 \cdot 50\right)$; beef meat, old cheese, white fish, pork meat and blue fish, in the case of energy consumption (all together: $R^{2}=0.36$ ); and beef meat, old cheese, pork meat, lamb meat and fresh cheese, for GHG emission (all together: $R^{2}=0 \cdot 64$; Table 2).

As shown in Fig. 2, eggs and meat and dairy products were the groups which contributed the most in all analysed outcomes: land use (22 and 19\%, respectively), water consumption (39 and $14 \%$, respectively), energy consumption ( 26 and $18 \%$, respectively) and GHG emission (46 and 19\%, respectively). Assessing the percentage contribution of specific items in the footprints, we showed that the most relevant for all of them was beef meat (9.4, 14.9, 6.4 and 18.6\%, for land, water and energy use, and GHG emission, respectively), followed by regular coffee $(6 \cdot 1 \%)$ in land use, olive oil $(5.9 \%)$ in water consumption, blue fish (5.6\%) in energy consumption and old cheese $(5.3 \%)$ in GHG emission.

\section{Discussion}

In the present study we observed that the better the adherence of our Spanish cohort to the MedDiet, the lower 
Table 2 Sources of variability (cumulative $R^{2}$ ) in total land use, water and energy consumption, and greenhouse gas (GHG) emission among 20363 participants in the Seguimiento Universidad de Navarra (SUN) cohort, 1999-2015

\begin{tabular}{llll}
\hline \multicolumn{3}{c}{ Cumulative $R^{2}$} \\
\hline Land use & Water consumption & Energy consumption & GHG emission \\
\hline Beef meat $(0.13)$ & Beef meat $(0.28)$ & Beef meat $(0.09)$ & Beef meat $(0.36)$ \\
Chocolate cookies $(0.25)$ & Olive oil $(0.35)$ & Old cheese $(0.17)$ & Old cheese $(0.46)$ \\
Old cheese $(0.35)$ & Pork meat $(0.41)$ & White fish $(0.24)$ & Pork meat $(0.54)$ \\
Regular coffee $(0.42)$ & Cured ham $(0.45)$ & Pork meat $(0.30)$ & Lamb meat $(0.59)$ \\
French fries $(0.47)$ & Asparagus $(0.50)$ & Blue fish $\dagger(0.36)$ & Fresh cheese $(0.64)$ \\
\hline
\end{tabular}

*'White fish' includes hake, seabream and sole. †'Blue fish' includes sardines, tuna and salmon.

(a)

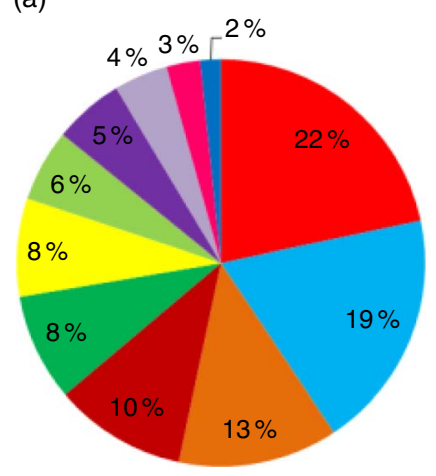

(c)

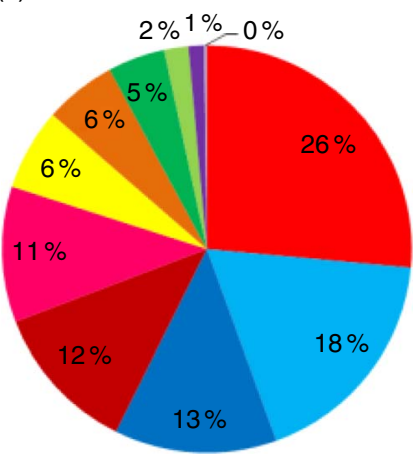

(b)

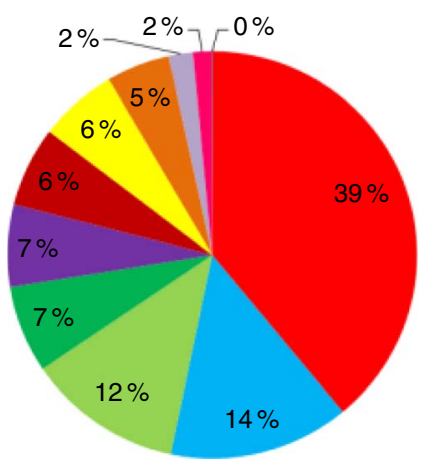

(d)

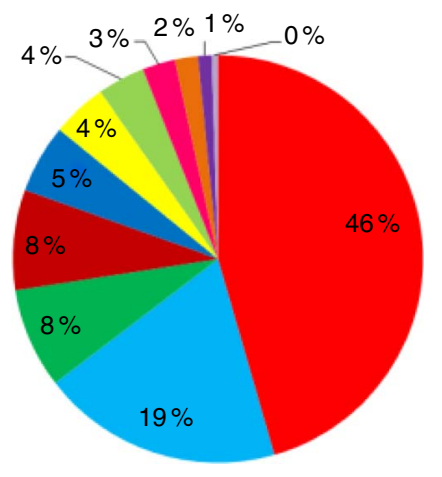

Dairy products

- Eggs and meat

- Fish and seafood

- Vegetables

- Fruits

Legumes

- Cereals

Fats and oils

Pastries

Beverages

Others

Fig. 2 Percentage of contribution of food groups to land use (a), water consumption (b), energy consumption (c) and greenhouse gas emission (d) among 20363 participants in the Seguimiento Universidad de Navarra (SUN) cohort, 1999-2015

was the land, water and energy use and GHG emission in the production of the foods for these diets. Our findings indicate that high adherence to the MedDiet is an ecofriendly option. Eggs, meat and dairy products were the food groups which most heavily contributed to a detrimental environmental impact in all analysed outcomes and the highest contributive item of all of them by far was beef meat.

Traditionally, professionals of nutrition used to assess diets exclusively according to their nutritional quality, ignoring their environmental consequences. In 1986, Gussow and Clancy started studying diets focusing not only on health but also on the environment footprints ${ }^{(16)}$, and in the last few years, a body of analysis has been carried out in relation to both aspects of diets. According to the present study, the MedDiet could be suggested as a healthy and eco-friendly example of a diet by a nutritionist giving dietary advice. From 1960, food production all around the world has increased in parallel with its population $^{(38)}$. Moreover, the global population is predicted to increase to about 9 billion people by $2050^{(39)}$. This increased size of the global population, in conjunction with changes in diet patterns and lifestyles, represents an impact on resource use and biodiversity loss ${ }^{(40,41)}$. The limitation of Earth's biophysical capacity may be kept in mind to adequately ponder the health 
consequences of the adoption of environmentally adverse dietary patterns.

The main environmental issues are loss of biodiversity, climate change, $\mathrm{N}$ and $\mathrm{P}$ cycle disruption, ozone depletion, acidification, global freshwater use and land use ${ }^{(42)}$. Most of the environmental footprint analyses have been assessed focusing on GHG emission, because it could be considered a good indicator for total environmental impact. Nevertheless, more studies are needed in relation to other aspects, such as resource or chemical use, or food wastage $^{(43,44)}$. In the current study we assessed not only GHG emission but also resource exploitation, because energy use, like GHG emission, is evocative of all environmental impacts and footprints ${ }^{(45)}$, land use is a good proxy for loss of biodiversity ${ }^{(46)}$ and water consumption is representative of freshwater loss and water pollution by agrochemicals. Thus, a macro perspective of the intertwined threats was carried out.

Current food production is the leading cause of deforestation, land-use change, water pollution and biodiversity loss. It is during the production stage when the greatest impacts occur, although the whole food chain contributes to these problems. In fact, food production accounts for 20-30\% of anthropogenic GHG emissions and contributes to $70 \%$ of all human water use ${ }^{(47,48)}$. Production of crops for livestock supposes a large environmental cost. For example, the rearing of livestock for meat, eggs and milk generates some $14.5 \%$ of total global GHG emissions and uses $70 \%$ of agricultural land, being the main driver of deforestation, biodiversity loss and land degradation ${ }^{(49)}$. This is also applicable to foods coming from water, because unsustainable fishing techniques disrupt the marine environment, depleting the species we consume.

The most relevant dietary distinctions in terms of environmental footprints are those between animal-based $v$. plant-based diets ${ }^{(50)}$. The MedDiet is mainly a plantcentred food pattern, although moderate to low amounts of animal foods are admitted. The fact that better adherence of participants in our cohort to the MedDiet was associated with decreased environmental pressures in all assessed dimensions confirms other previous investigations that concluded that a shift towards a MedDiet would reduce GHG emission and resource use $\mathrm{e}^{(50-52)}$. We used the index of adherence to the MedDiet proposed by Trichopoulou et $a l .{ }^{(29)}$ because it is largely used in nutritional public health studies and because its validity has been previously checked ${ }^{(53,54)}$. It has been reported that a vegetarian or vegan diet could be more environmentally advantageous than other diets which include animal products ${ }^{(20,55)}$ and that a reduction in meat consumption would ease pressure on footprints ${ }^{(56)}$. Thus, a shift, even a gentle and moderate shift to less animalbased and more plant-based diets, like the MedDiet or the pro-vegetarian diet, may be positive not only for reducing all-cause mortality ${ }^{(57)}$ but also for the environment ${ }^{(17,18,20)}$. For example, legumes are stated as alternatives to animal-protein foods ${ }^{(17)}$ because production of $1 \mathrm{~kg}$ of protein from beef supposes eighteen, ten and nine times more land, water and fuel use, respectively, than production of the same quantity of protein from beans ${ }^{(58)}$. Our results showed, in accordance with other previous studies, that animal-based foods, especially eggs, meat and dairy products, showed a remarkable environmental footprint in all the analysed outcomes, with also a large contribution of fish in the case of energy consumption. Nevertheless, it should be noticed that the increases in land use over time have depended not only on meat consumption, but also on the consumption of beverages like beer, wine or coffee, whose origins are vegetal $^{(59)}$.

From a health point of view, moving to diets with fewer animal-based foods would be beneficial ${ }^{(55,60-63)}$. However, some have suggested that diets based exclusively on plant products are not as healthy as others that include small amounts of animal foods, like the Mediterranean $^{(64)}$. Replacing red meat with white meat could reduce environmental impact (i.e. according to our data, substituting one serving of beef meat by one of chicken supposes a reduction of $2.16 \mathrm{~m}^{2}$ of land, 1664.5 litres of water, $1.911 \mathrm{MJ}$ of energy and $2.013 \mathrm{~kg}$ of $\mathrm{CO}_{2} \mathrm{e}$; and replacing a serving of pork meat by one of chicken $0.48 \mathrm{~m}^{2}$ of land, 249.45 litres of water, $1.254 \mathrm{MJ}$ of energy and $0.276 \mathrm{~kg}$ of $\mathrm{CO}_{2} \mathrm{e}$ ) and from a general health point of view, the latter is more favourable ${ }^{(65)}$. Fish consumption two or three times weekly is highly recommendable from a health point of view ${ }^{(66-68)}$, although this recommendation might be ecologically detrimental. It is necessary, therefore, to reinforce its consumption from recognized sustainable sources, and in the case of wild-caught fish, from species that are not being overfished. Because of that, bearing in mind both aspects of health and environment repercussion, the MedDiet might be one of the healthiest dietary patterns with a relatively low environmental impact ${ }^{(64,69,70)}$.

New priorities for the public health agenda will be required for the health-environment-diet trilemma ${ }^{(56)}$. Global dietary patterns have changed in the last years, and the population tends more and more to consume foods with negative impacts on health and the environment, such as red meats or processed foods ${ }^{(40)}$. Dietary changes are important for promoting improved public health; at the same time healthier diets can reduce the pressures of the agricultural and food systems on the environment ${ }^{(64,71)}$.

Innovative strategies are required to comprehensively assess food systems, which should take account of the health, nutritional and environmental aspects of foods. The environment and public health communities are in a position to reinforce each other's efforts for working with the general public, governments and corporations. Globally, interest is growing in the scope for designing guidelines that advise on dietary patterns that align health and environmental objectives. However, few dietary 
guidelines incorporate all these aspects nowadays ${ }^{(72)}$. So, more efforts are needed to foster food-choice trends into an eco-friendlier direction.

The major novelty of the current study is that it investigated the relationship between the MedDiet and environmental footprints in a large sample of people from a Mediterranean setting, using the actual habits of consumption. The self-reported dietary information provides a better estimate of the diet than other Spanish analysis based on food balance sheets and household consumption surveys ${ }^{(52)}$. The present study is the first (or one of the very first) direct investigations on the actual environmental impact of the MedDiet measured within a population sample (even though not representative of the general population). Other strengths of our study include the previous validation of the questionnaires used, the high number of food items assessed, the use of a wide range of outcome measures and a relatively large sample size.

Limitations of the study are that the data used to assess environmental footprint have not been recently published and some came from different countries and with different methodologies; furthermore, data for every food on the questionnaire in every analysis were not available. The current investigation studied the effect of diet on the environment according to food production and processing. Other phases of the food chain like packaging, transportation, retailing, cooking and waste disposal go beyond the scope of the present paper. We only took account of conventional agriculture processes and no other alternative ways. Moreover, we analysed resource use and GHG emission only, and no other damaging inputs (like pesticide and fertilizer usage) or outputs (such as waste disposal). For a more comprehensive assessment of the environmental impacts of the diet, these impact categories should also be included in future studies.

\section{Conclusions}

Our study found that a better adherence to the MedDiet was an eco-friendly option, associated with less environmental footprints, including lower land, water and energy use and GHG emission. The amount of animal-based foods in the diet, particularly meat and dairy products, was the most significant contributor to the harms for the environment and to a suboptimal sustainability, with beef meat consumption having relevant interest. Nevertheless, to advance this work, better available information must be developed. Other studies based on actual individual food consumption are required to confirm our results. As diet influences positively not only our health but also the environment, a nutritionist giving dietary advice may take the environmental impact of diet into account, and enhanced adherence to a MedDiet is likely to be an important target to be fostered in our society.

\section{Acknowledgements}

Acknowledgements: The authors are thankful to Peter Scarborough for his comments on an early version of this manuscript, as well as to the participants of the SUN cohort for their continuous involvement in the project and all members of the SUN study for their support and collaboration. Financial support: The Seguimiento Universidad de Navarra (SUN) Project has received funding from the Spanish Government, Instituto de Salud Carlos III and the European Regional Development Fund (M.-A.M.-G., grant numbers FEDER, CIBER-OBN, G03/ 140), (M.B.-R., grant numbers PI10/02293, PI13/00615, PI14/01668); the Navarra Regional Government (M.B.-R., grant numbers 45/2011, 122/2014); and the University of Navarra. None of the funders had any role in the design, analysis or writing of this article. Conflict of interest: None. Authorship: Conception and design: U.F. and M.B.-R. Acquisition, analysis and interpretation of data: U.F. and M.B.-R. Statistical analysis: U.F. Drafting of the manuscript: U.F. Critical revision of the manuscript for important intellectual content: J.S., M.-A.M.-G. and M.B.-R. Obtaining funding: M.-A.M.-G. and M.B.-R. Supervision: M.B.-R. Ethics of buman subject participation: All procedures performed in studies involving human participants were in accordance with the ethical standards of the Institutional Review Board Research Ethics Committee of the University of Navarra and with the 1964 Helsinki Declaration and its later amendments or comparable ethical standards. Informed consent was obtained from all individual participants included in the study.

\section{Supplementary material}

To view supplementary material for this article, please visit https://doi.org/10.1017/S1368980017003986

\section{References}

1. Bach-Faig A, Berry EM, Lairon D et al. (2011) Mediterranean diet pyramid today. Science and cultural updates. Public Health Nutr 14, 2274-2284.

2. Trichopoulou A \& Lagiou P (1997) Healthy traditional Mediterranean diet: an expression of culture, history, and lifestyle. Nutr Rev 55, 383-389.

3. Willett WC, Sacks F, Trichopoulou A et al. (1995) Mediterranean diet pyramid: a cultural model for healthy eating. Am J Clin Nutr 61, 6 Suppl., 1402S-1406S.

4. Sanchez-Tainta A, Zazpe I, Bes-Rastrollo M et al. (2016) Nutritional adequacy according to carbohydrates and fat quality. Eur J Nutr 55, 93-106.

5. Serra-Majem L, Bes-Rastrollo M, Roman-Vinas B et al. (2009) Dietary patterns and nutritional adequacy in a Mediterranean country. Br J Nutr 101, Suppl. 2, S21-S28.

6. Bosetti C, Pelucchi C \& La Vecchia C (2009) Diet and cancer in Mediterranean countries: carbohydrates and fats. Public Health Nutr 12, 1595-1600.

7. Buckland G, Bach A \& Serra-Majem L (2008) Obesity and the Mediterranean diet: a systematic review of observational and intervention studies. Obes Rev $\mathbf{9}, 582-593$. 
8. Estruch R, Ros E, Salas-Salvado J et al. (2013) Primary prevention of cardiovascular disease with a Mediterranean diet. N Engl J Med 368, 1279-1290.

9. Martinez-Gonzalez MA, Bes-Rastrollo M, Serra-Majem L et al. (2009) Mediterranean food pattern and the primary prevention of chronic disease: recent developments. Nutr Rev 67, Suppl. 1, S111-S116.

10. Martinez-Gonzalez MA \& Martin-Calvo N (2016) Mediterranean diet and life expectancy; beyond olive oil, fruits, and vegetables. Curr Opin Clin Nutr Metab Care 19, 401-407.

11. Serra-Majem L, Roman B \& Estruch R (2006) Scientific evidence of interventions using the Mediterranean diet: a systematic review. Nutr Rev 64, 2 Pt 2, S27-S47.

12. Sofi F, Cesari F, Abbate R et al. (2008) Adherence to Mediterranean diet and health status: meta-analysis. BMJ 337, a1344.

13. Trichopoulou A, Martinez-Gonzalez MA, Tong TY et al. (2014) Definitions and potential health benefits of the Mediterranean diet: views from experts around the world. BMC Med 12, 112.

14. United Nations Educational, Scientific and Cultural Organization (2013) Representative List of the Intangible Cultural Heritage of Humanity. http://www.unesco.org/culture/ich/ en/lists (accessed September 2016).

15. Donini LM, Dernini S, Lairon D et al. (2016) A consensus proposal for nutritional indicators to assess the sustainability of a healthy diet: the Mediterranean diet as a case study. Front Nutr 3, 37.

16. Gussow JD \& Clancy KL (1986) Dietary guidelines for sustainability. J Nutr Educ 18, 1-5.

17. Carlsson-Kanyama A \& Gonzalez AD (2009) Potential contributions of food consumption patterns to climate change. Am J Clin Nutr 89, issue 5, 1704S-1709S.

18. Baroni L, Cenci L, Tettamanti M et al. (2007) Evaluating the environmental impact of various dietary patterns combined with different food production systems. Eur J Clin Nutr 61 , 279-286.

19. Pimentel D \& Pimentel M (2003) Sustainability of meatbased and plant-based diets and the environment. Am J Clin Nutr 78, 3 Suppl., 660S-663S.

20. Reijnders L \& Soret S (2003) Quantification of the environmental impact of different dietary protein choices. Am J Clin Nutr 78, 3 Suppl., 664S-668S.

21. Burlingame B \& Dernini S (2012) Sustainable Diets and Biodiversity: Directions and Solutions for Policy, Research and Action. Proceedings of the International Scientific Symposium 'Biodiversity and Sustainable Diets United Against Hunger', 3-5 November 2010, FAO Headquarters, Rome. http://www.fao.org/docrep/016/i3004e/i3004e.pdf (accessed September 2016).

22. Gussow JD (1995) Mediterranean diets: are they environmentally responsible? Am J Clin Nutr 61, issue 6, 1383S-1389S.

23. Burlingame B \& Dernini S (2011) Sustainable diets: the Mediterranean diet as an example. Public Health Nutr $\mathbf{1 4}$ 2285-2287.

24. Dernini S, Berry EM, Serra-Majem L et al. (2017) Med Diet 4.0: the Mediterranean diet with four sustainable benefits. Public Health Nutr 20, 1322-1330.

25. Germani A, Vitiello V, Giusti AM et al. (2014) Environmental and economic sustainability of the Mediterranean diet. Int J Food Sci Nutr 65, 1008-1012.

26. Leon-Munoz LM, Guallar-Castillon P, Graciani A et al. (2012) Adherence to the Mediterranean diet pattern has declined in Spanish adults. J Nutr 142, 1843-1850.

27. Vareiro D, Bach-Faig A, Raido Quintana B et al. (2009) Availability of Mediterranean and non-Mediterranean foods during the last four decades: comparison of several geographical areas. Public Health Nutr 12, 1667-1675.
28. Varela-Moreiras G, Avila JM, Cuadrado C et al. (2010) Evaluation of food consumption and dietary patterns in Spain by the Food Consumption Survey: updated information. Eur J Clin Nutr 64, Suppl. 3, S37-S43.

29. Trichopoulou A, Costacou T, Bamia C et al. (2003) Adherence to a Mediterranean diet and survival in a Greek population. $N$ Engl J Med 348, 2599-2608.

30. Martinez-Gonzalez MA, Sanchez-Villegas A, De Irala J et al. (2002) Mediterranean diet and stroke: objectives and design of the SUN project. Seguimiento Universidad de Navarra. Nutr Neurosci 5, 65-73.

31. Martinez-Gonzalez MA (2006) The SUN cohort study (Seguimiento University of Navarra). Public Health Nutr 9 , 127-131.

32. Segui-Gomez M, de la Fuente C, Vazquez Z et al. (2006) Cohort profile: the 'Seguimiento Universidad de Navarra' (SUN) study. Int J Epidemiol 35, 1417-1422.

33. Willett WC (2013) Nutritional Epidemiology, 3rd ed. New York: Oxford University Press.

34. Martin-Moreno JM, Boyle P, Gorgojo L et al. (1993) Development and validation of a food frequency questionnaire in Spain. Int J Epidemiol 22, 512-519.

35. de la Fuente-Arrillaga C, Ruiz ZV, Bes-Rastrollo M et al. (2010) Reproducibility of an FFQ validated in Spain. Public Health Nutr 13, 1364-1372.

36. Fernandez-Ballart JD, Pinol JL, Zazpe I et al. (2010) Relative validity of a semi-quantitative food-frequency questionnaire in an elderly Mediterranean population of Spain. BrJ Nutr 103, 1808-1816.

37. Bustos A (1999) 777 Recetas de Cocina Inteligente, 4th ed. Spain: Ediciones Internacionales Universitarias.

38 Pretty J (2008) Agricultural sustainability: concepts, principles and evidence. Philos Trans R Soc Lond B Biol Sci 363 , $447-465$.

39. Food and Agriculture Organization of the United Nations (2009) How to Feed the World in 2050. http://www.fao.org/ fileadmin/templates/wsfs/docs/expert_paper/How_to_Feed_ the_World_in_2050.pdf (accessed September 2016).

40. Johnston JL, Fanzo JC \& Cogill B (2014) Understanding sustainable diets: a descriptive analysis of the determinants and processes that influence diets and their impact on health, food security, and environmental sustainability. $A d v$ Nutr 5, 418-429.

41. Galli A, Iha K, Halle M et al. (2017) Mediterranean countries' food consumption and sourcing patterns: an ecological footprint viewpoint. Sci Total Environ 578, 383-391.

42. Rockstrom J, Steffen W, Noone K et al. (2009) A safe operating space for humanity. Nature 461, 472-475.

43. Heller MC, Keoleian GA \& Willett WC (2013) Toward a life cycle-based, diet-level framework for food environmental impact and nutritional quality assessment: a critical review. Environ Sci Technol 47, 12632-12647.

44. Sabate J, Harwatt H \& Soret S (2016) Environmental nutrition: a new frontier for public health. Am J Public Health 106, 815-821.

45. Dutilh CE \& Krammer KJ (2000) Energy consumption in the food chain: comparing alternative options in food production and consumption. AMBIO 29, 98-101.

46. Pereira HM, Leadley PW, Proenca V et al. (2010) Scenarios for global biodiversity in the 21st century. Science 330, 1496-1501.

47. Edenhofer O, Pichs-Madruga R, Sokona Y et al. (2014) Climate Change 2014: Mitigation of Climate Change. Working Group III Contribution to the Fifth Assessment Report of the Intergovernmental Panel on Climate Change. New York: Cambridge University Press; available at http://www.ipcc.ch/ pdf/assessment-report/ar5/wg3/ipcc_wg3_ar5_full.pdf

48. Johnson JA, Runge CF, Senauer B et al. (2014) Global agriculture and carbon trade-offs. Proc Natl Acad Sci US A 111, 12342-12347. 
49. Gerber PJ, Steinfeld H, Henderson B et al. (2013) Tackling Climate Change Through Livestock: A Global Assessment of Emissions and Mitigation Opportunities. Rome: FAO.

50. Sabate J \& Soret S (2014) Sustainability of plant-based diets: back to the future. Am J Clin Nutr 100, Suppl. 1, 476S-482S.

51. US Department of Health and Human Services \& US Department of Agriculture (2015) 2015-2020 Dietary Guidelines for Americans, 8th ed. Washington, DC: DHHS and USDA; available at http://www.health.gov/ dietaryguidelines/2015/guidelines/

52. Saez-Almendros S, Obrador B, Bach-Faig A et al. (2013) Environmental footprints of Mediterranean versus Western dietary patterns: beyond the health benefits of the Mediterranean diet. Environ Health 12, 118.

53. Bach A, Serra-Majem L, Carrasco JL et al. (2006) The use of indexes evaluating the adherence to the Mediterranean diet in epidemiological studies: a review. Public Health Nutr 9, 132-146.

54. Mila-Villarroel R, Bach-Faig A, Puig J et al. (2011) Comparison and evaluation of the reliability of indexes of adherence to the Mediterranean diet. Public Health Nutr 14, 2338-2345.

55. Marlow HJ, Harwatt H, Soret S et al. (2015) Comparing the water, energy, pesticide and fertilizer usage for the production of foods consumed by different dietary types in California. Public Health Nutr 18, 2425-2432.

56. Tilman D \& Clark M (2014) Global diets link environmental sustainability and human health. Nature 515, 518-522.

57. Martinez-Gonzalez MA, Sanchez-Tainta A, Corella D et al. (2014) A provegetarian food pattern and reduction in total mortality in the Prevencion con Dieta Mediterranea (PREDIMED) study. Am J Clin Nutr 100, Suppl. 1, 320S-328S.

58. Sranacharoenpong K, Soret S, Harwatt $\mathrm{H}$ et al. (2015) The environmental cost of protein food choices. Public Health Nutr 18, 2067-2073.

59. Gerbens-Leenes PW \& Nonhebel S (2002) Consumption patterns and their effects on land required for food. Ecol Econom 42, 185-199.

60. Le LT \& Sabate J (2014) Beyond meatless, the health effects of vegan diets: findings from the Adventist cohorts. Nutrients 6, 2131-2147.

61. Orlich MJ, Singh PN, Sabate J et al. (2013) Vegetarian dietary patterns and mortality in Adventist Health Study 2. JAMA Intern Med 173, 1230-1238.
62. Satija A, Bhupathiraju SN, Rimm EB et al. (2016) Plant-based dietary patterns and incidence of type 2 diabetes in US men and women: results from three prospective cohort studies. PLOS Med 13, e1002039.

63. Springmann M, Godfray HC, Rayner M et al. (2016) Analysis and valuation of the health and climate change cobenefits of dietary change. Proc Natl Acad Sci U S A 113, $4146-4151$.

64. van Dooren C, Marinussen M, Blonk H et al. (2014) Exploring dietary guidelines based on ecological and nutritional values: a comparison of six dietary patterns. Food Policy 44, 36-46.

65. Becerra-Tomas N, Babio N, Martinez-Gonzalez MA et al. (2016) Replacing red meat and processed red meat for white meat, fish, legumes or eggs is associated with lower risk of incidence of metabolic syndrome. Clin Nutr 35, 1442-1449.

66. Calder PC (2006) n-3 Polyunsaturated fatty acids, inflammation, and inflammatory diseases. Am J Clin Nutr 83, 6 Suppl., 1505S-1519S.

67. Sanchez-Villegas A, Henriquez P, Figueiras A et al. (2007) Long chain omega-3 fatty acids intake, fish consumption and mental disorders in the SUN cohort study. Eur J Nutr 46, 337-346.

68. Sociedad Española de Nutrición Comunitaria (2015) Pirámide de la Alimentación Saludable 2015. http:// www.nutricioncomunitaria.org/es/noticia/piramide-dela-alimentacion-saludable-senc-2015 (accessed September 2016).

69. Duchin F (2005) Sustainable consumption of food: a framework for analyzing scenarios about changes in diets. I Ind Ecol 9, 99-114.

70. Nelson ME, Hamm MW, Hu FB et al. (2016) Alignment of healthy dietary patterns and environmental sustainability: a systematic review. Adv Nutr 7, 1005-1025.

71. Ruini LF, Ciati R, Pratesi CA et al. (2015) Working toward healthy and sustainable diets: the 'Double Pyramid Model' developed by the Barilla Center for Food and Nutrition to raise awareness about the environmental and nutritional impact of foods. Front Nutr $\mathbf{2}, 9$.

72. Gonzalez C \& Garnett T (2016) Plates, pyramids, planet. Developments in national healthy and sustainable dietary guidelines: a state of play assessment. http://www.fao.org/ 3/a-i5640e.pdf (accessed November 2016). 